\title{
A qualitative comparison of South Africa's geomatics professional body's academic model against industry's understanding of SDI knowledge and skills requirements
}

\author{
Serena Coetzee ${ }^{\mathrm{a}, 1}$, Victoria Rautenbach ${ }^{\mathrm{a}}$, and Heindrich du Plessis ${ }^{\mathrm{b}}$ \\ ${ }^{a}$ Centre for Geoinformation Science, Department of Geography, Geoinformatics and \\ Meteorology, University Pretoria, Pretoria, South Africa \\ ${ }^{b}$ Department Rural Development and Land Reform, Cape Town, South Africa
}

The South African Spatial Data Infrastructure (SASDI) was established in 2003. Registration of geographical information science (GISc) practitioners by the South African geomatics professional body followed in 2004 and accreditation of university GISc programmes in 2012. In 2010 the Committee for Spatial Information (CSI) identified inadequate knowledge and skills of GISc practitioners as a challenge for the implementation and maintenance of SASDI. In response, spatial data infrastructure (SDI) knowledge and skills requirements for GISc professionals were specified by GISc industry representatives and the professional body's academic model was qualitatively compared against these requirements. Results are discussed and improvements recommended.

Keywords: spatial data infrastructure; GISc education; professional body; registration; accreditation; South Africa

\section{Introduction}

The South African Spatial Data Infrastructure (SASDI) framework was established in terms of Act 54 of 2003 (South Africa, 2003). Subsequently in 2004, the South African geomatics professional body launched an intensive drive to register geographical information science (GISc) practitioners who meet certain minimum competency requirements, described in its academic model. Using this model the professional body commenced with the accreditation of university programmes offering GISc education in 2012. The Committee for Spatial Information (CSI), with

\footnotetext{
${ }^{1}$ Corresponding author. Email: serena.coetzee@up.ac.za
} 
an advisory role for SASDI, was established in terms of the SASDI legislation and commenced its work in 2010. The CSI identified the inadequate knowledge and skills of professional GISc practitioners in South Africa as one of its first challenges for successful implementation and maintenance of SASDI.

To address the problem, spatial data infrastructure (SDI) knowledge and skills requirements for GISc professionals were specified by representatives of the South African GISc industry, also drawing on secondary data. The academic model of the South African geomatics professional body, which is used for the registration of GISc practitioners and the accreditation of university GISc programmes, was qualitatively compared against these requirements. Drawing on the comparison, recommendations are made to improve the knowledge base dealing with SDI education in the professional body's academic model. These recommendations can be used to refine the academic model and to guide developers of GISc programmes at universities. Further research opportunities are also identified.

The research presented in this article is of relevance to SDI developments all over the world. SDIs are complex, dynamic and multifaceted (Grus et al., 2010) and success relies heavily on people (Richter et al. 2010). GISc education is seen as a crucial contributor to the success of an SDI (Boes \& Pavlova, 2011; Hendriks et al., 2012; Skender, 2013) and researchers have included education as a measurable variable for capacity building in the assessment of SDIs in developing countries (Eelderink et al., 2008). Crompvoets \& Bregt (2005) noted a worldwide decline in the use, management and content of SDI clearinghouses. The omission of SDI topics from specific GISc curricula has been reported; for example, in Germany and Japan (Ota, 2012; Reinhardt 2011). Without proper GISc education and awareness of the benefits of SDIs, the decline in the management, distribution and accessibility of geospatial data will continue with subsequent costs and negative developmental implications for the countries.

The next two sections of the article provide background about the South African geomatics professional body, registration of GISc professionals and SASDI. In these sections research gaps are clarified and research objectives described. The subsequent section describes how the research objectives were achieved, followed by a section in which the qualitative research method is applied to compare the academic model of the professional body against the SDI knowledge and skills requirements. Results are discussed and recommendations made in the next section, followed by the conclusion. 


\section{The South African geomatics professional body and registration of GISc professionals}

The South African geomatics profession executes its duties and responsibilities within a regulated environment that includes a Code of Conduct to protect the interest of the public and to offer recourse in the form of disciplinary hearings and sanctions. Act 40 of 1984 established the South African Council for Professional and Technical Surveyors (PLATO) as a professional body for the geomatics profession (South Africa, 1984). The responsibilities of the geomatics professional body include the registration of persons who practice GISc, as well as the accreditation of university GISc degree programmes. In December 2013, the Geomatics Profession Act 19 of 2013 replaced this Act and the South African Council for Geomatics Professionals is established accordingly (South Africa, 2013). PLATO will remain as a transitional council and all persons registered with PLATO, as well as the accredited university programmes, will be recognised and transferred to the registers of the new Council.

In terms of the new legislation, effective from 2014, all persons practicing in any of the geomatics branches are required to be registered with an appropriate professional body. GISc is recognised in the new legislation as one of the branches of the geomatics profession and consequently it is a requirement that any person practicing in the GISc field as a technician, technologist or professional practitioner is registered with the geomatics professional body. In order to qualify for registration or accreditation, applicants must meet certain minimum criteria specified by the professional body described in its academic model.

A combination of competencies in knowledge (cognitive), skills (functional), and behaviours and attitudes (social and meta) are required for certain occupations, i.e. individuals need to be competent (possess the required skills and knowledge) to achieve a mutual goal (Flamholtz \& Lacey, 1981). The term 'competence' bridges the gap between education and job requirements (Le Deist \& Winterton, 2005).

The academic model of the geomatics professional body provides a framework for cognitive and functional competence requirements. Such a competence based approach defines learning outcomes which state what learners are expected to know, understand and do upon completion of their education. The model is regarded as the baseline for the education of professionals practicing in the GISc field in South Africa. The curricula and standard of education at universities are compared against the academic model, using criteria such as themes, topics and lecture hours. 
Table 1 lists the themes and lecture hours in the academic model, while Table 2 lists topics for one of the themes in the academic model namely 3D-Modeling/ Cartography/Visualisation. Common themes are study areas for all branches of the geomatics profession, i.e. surveying, photogrammetry, mine-surveying and GISc. Category-specific themes are relevant to a specific branch of geomatics only. Each theme comprises a list of topics. For example, the topics of the geographical science theme are 'Geography and its nature and prospective, population, cultural patterns and processes, political organisation of space, agricultural and rural land use, industrialisation, cities and urban land use, physical geography.' The academic model does not specify topics for the Category-specific Research Project and Electives themes, implying that universities are free to customise this content to suit their needs. They could also leave the choice of topics open to students. The complete model, themes and topics, can be viewed at www.plato.org.za.

Table 1. Themes in the GISc academic model of the geomatics professional body

\begin{tabular}{llc}
\hline \multicolumn{1}{c}{ Type of theme } & \multicolumn{1}{c}{ Theme name } & Lecture hours \\
\hline Common themes for all & Mathematics, Applied Mathematics and Statistics & 100 \\
branches in the & Physics & 25 \\
geomatics profession & Information Technology & 75 \\
& Geospatial Information Science & 175 \\
& Photogrammetry and Remote Sensing & 75 \\
& Coordinate Systems and Map Projections & 50 \\
& Business and Project Management & 25 \\
& Professional Practice and Ethics & 25 \\
& Category-specific Research Project & 75 \\
\hline Category-specific & 3D-Modeling/Cartography/Visualisation & 75 \\
themes for GISc & Data Acquisition & 65 \\
& Geographical Science & 50 \\
Source: Website & Elective Study Areas & 385 \\
thww.plato.org.za & South African Council for Professional and Technical Surveyors & (PLATO), \\
\hline
\end{tabular}

Table 2. Topics listed for the theme, 3D-Modeling/Cartography/Visualisation, in the GISc academic model of the geomatics professional body

\begin{tabular}{ll}
\hline \multicolumn{1}{c}{ Theme name } & \multicolumn{1}{c}{ Topics } \\
\hline 3D-Modeling/ & Visual perception, graphicacy, cartographic communication (including information sense- \\
Cartography/ & making, information use and information-knowledge transformation), graphic space, \\
Visualisation & semiotics, symbolization, map representation, colour, cartographic design, typonomy, \\
& $\begin{array}{l}\text { generalization, map use, multimedia mapping, 2-D and 3-D visualization, interactive } \\
\text { maps, Web maps, Virtual Globes, general purpose maps, relief representation, thematic } \\
\text { maps (including statistical mapping), image maps, intellectual property and copyright, } \\
\text { privacy rights, information economics, computer-assisted cartography systems, and map } \\
\text { printing. }\end{array}$ \\
& \\
\hline Source: Website of the South African Council for Professional and Technical Surveyors (PLATO), \\
www.plato.org.za
\end{tabular}


GISc degree programmes were only recently introduced at universities in South Africa, with the first programmes being accredited in 2012. However, employers and employees in the GISc field have for a long time demanded GISc education and training from universities and the professional body. Consequently, PLATO commenced as early as 2004 with a dedicated drive to register persons practicing in the GISc field through the provision of a grandfather clause dispensation, enabling persons with GISc experience but without a formal GISc qualification to register with the professional body. Therefore South Africa is in the unique situation that the majority of the GISc professionals who registered between 2004 and 2013 completed a different but related first degree, for example, in geography, surveying or computer science. They do however have extensive appropriate experience in the GISc field.

Since 2004, registration with the professional body has increasingly been used to specify human resource requirements in tenders and employment opportunities of government departments (South Africa, 2009). Considering the importance of spatial information and SDIs to government, SDI concepts are an important ingredient of GISc education and training at institutions of higher education. However, it is not known whether the themes in the South African academic model adequately cover SDI concepts to prepare GISc professionals for their important role in SASDI.

\section{The South African Spatial Data Infrastructure (SASDI)}

SDIs developed to support government activities when paper maps and corresponding cartographic production arrangements were being replaced by digital geographic information (Masser \& Campbell, 1991). Today, SDIs facilitate the discovery of and access to harmonised spatial data through a combination of technology, systems, standards, networks, people, policies, organisational aspects, georeferenced data, and delivery mechanisms to end users (Georgiadou et al., 2005; Jackson \& Gardner, 2011). SDIs have been established in many countries and regions, for example, Australia, USA, India and the Infrastructure for Spatial Information in Europe (INSPIRE). Act 54 of 2003 (South Africa, 2003) establishes SASDI as 'the national technical, institutional and policy framework to facilitate the capture, management, maintenance, integration, distribution and use of spatial information'. In terms of the Act, in 2010, the CSI was established with an advisory role on spatial information.

An SDI plays an important role in facilitating sustainable development because it aims to facilitate and coordinate access to and exchange of geographic information 
within all sectors and levels of society (Hjelmager et al., 2008; Nebert, 2009). SDIs are complex, dynamic and multifaceted (Grus et al., 2010) and the successful implementation of an SDI in any country relies heavily on a workforce competent in the relevant knowledge (Richter et al., 2010; Beconytê et al., 2008).

The CSI through various interactions, including workshops and surveys, has identified GISc skills shortages and SDI expertise as a potential impediment to the successful development of SASDI, leading to the establishment of the CSI subcommittee on Education and Training in 2011 (Rautenbach et al., 2012). Two problems contribute to the shortage of professionally registered GISc practitioners in South Africa: (1) inconsistencies in the knowledge and skills development of GISc professionals; and (2) challenges facing universities to design curricula to prepare learners for registration with the geomatics professional body. These problems are aggravated by the significant variation in content, outcomes and quality of GISc education offered by different universities. The situation is unlikely to improve unless a curriculum framework for GISc is established with clear guidelines on minimum requirements for SDI topics, according to which university programmes can be evaluated for accreditation (Du Plessis \& Van Niekerk, 2013).

Competence is seen as a crucial contributor to the success of an SDI implementation (Boes \& Pavlova, 2011; Hendriks et al., 2012; Skender, 2013) and researchers have included education and training as a measurable variable for capacity building in the assessment of SDIs in developing countries (Eelderink et al., 2008). In previous studies GISc competencies and curricula have been widely analysed (DiBiase et al., 2006; Messina \& Shortridge, 2006; DeMers, 2009; Coetzee et al., 2013; Du Plessis \& Van Niekerk, 2013; Schulze et al., 2013). However, research about the appropriateness of these curricula in the context of SDIs is limited (Boes \& Pavlova, 2011).

An exception is the work of Reinhardt (2011) who showed that the SDI topic is not adequately described in the UCGIS GI S\&T BoK and suggested to extend the BoK with an SDI knowledge area for which a number of topics are proposed. The list of topics was compiled from the author's understanding of SDI knowledge and skills requirements.

The research reported in this article describes industry's understanding of SDI knowledge and skills requirements against which the academic model of the South African geomatics professional body is compared in order to identify inconsistencies 
between the requirements and the academic model. The objectives are to contribute towards the work of the CSI sub-committee on Education and Training; to inform a refinement of the academic model; and to guide programme developers at universities.

\section{Method}

To achieve the research objectives, SDI knowledge and skills required by GISc professionals to contribute to SASDI were identified and grouped into a number of SDI topics. The requirements were identified based on a review of SDIs in scientific literature and with input from the GISc industry in South Africa. The topics were qualitatively compared against the themes and topics in the academic model. The results are analysed and discussed in this article. Recommendations are made to refine the academic model and guide developers of university GISc programmes. Further research opportunities are also identified.

The SDI knowledge and skills requirements were identified (see Table 3) using secondary data derived from a literature review of SDI concepts, definitions and components; two workshops with a representative group from the GISc industry in South Africa; and a review of books as potential education and training material.

The initial list of SDI topics derived from the literature review was refined during two workshops held at the University of Pretoria in November 2011 and July 2012 with representatives from the GISc industry, including academics, professional practitioners in the private and public sector and GISc service providers. The majority of workshop participants were registered GISc professionals; all of them were members of the CSI sub-committee on Education and Training. Members comprise CSI members with an interest in Education and Training, as well as members invited and co-opted to contribute to the sub-committee due to their expertise and interest in GISc and/or SDI education and training.

During the workshops target audiences, media and messages for SDI education and training in South Africa were identified. The aim was to answer the question: Who needs to be educated and trained? What SDI knowledge and skills do they need in order to contribute to SASDI? How can they be educated and/or trained? Firstly, seven target audiences were identified, based on their different roles in SASDI: 1) CSI members; 2) decision makers, funders, and policy makers; 3) custodians of SASDI identified base data sets; 4) producers of SASDI non-base data sets; 5) 
producers of SASDI services; 6) providers of SASDI base data sets and services; and 7) end users and consumers of SASDI data sets and services through providers.

Secondly, knowledge and skills that each target audience should have in order to contribute effectively to the development of SASDI were described. These are descriptions of the messages that should be delivered to the target audiences. The messages were grouped into the following 18 knowledge areas:

1. The value of spatial information for their respective purpose or job in SASDI

2. Spatial data and the principles of geographic information systems (GIS)

3. Overview of SDI, SDI principles and its benefits

4. SDI component: data and metadata

5. SDI component: standards and specifications

6. SDI component: web services

7. SDI component: institutional agreements

8. Laws other than the SDI Act related to SASDI, e.g. copyright and intellectual property right laws

9. Relevant knowledge areas in the South African GISc academic model

10. SASDI and its providers

11. SASDI and the benefits to their respective purposes of participating

12. SASDI base data and associated services

13. SASDI policy and legal issues

14. Legislative responsibilities inferred on participants by the SDI Act

15. Information and/or training that providers have to pass on to users

16. Design and use of SASDI tools (e.g. a geoportal or clearinghouse)

17. Service implementation according to SASDI guidelines

18. SASDI prescribed tools and technologies

Thirdly, appropriate media for the delivery of the messages were identified, such as written documentation, workshops, attendance courses and tertiary education.

Finally, each knowledge area was matched with target audiences, media and an appropriate level of specialization (awareness, knowledge, skills, etc.). For example, the 'Overview of SDI, SDI principles and its benefits'-message should be delivered through media, such as workshops, attendance courses and written documentation to the CSI members target audience at a knowledge level, while it should be delivered to decision makers funders and policy makers through one-on-one discussions, 
presentations and written documentation at an awareness level (Rautenbach et al., 2012).

Subsequently, Rautenbach \& Coetzee (2013) completed a survey of books for use as SDI education and training material. The books were categorised according to their content into the following categories: GISc; Data or information; Standards, Technical; Policies and Legislation; People; Economics; and Combination of themes. These categories were then matched to the earlier identified knowledge areas that are not SASDI specific (because books about SASDI have not yet been published). This provides a mapping between the book categories and the SDI knowledge and skills requirements identified for SASDI at the workshops.

The SDI topics presented in Tables 3 and 4 draw on the book categories, but are aligned with the Geographic Information Science and Technology Body of Knowledge (GI S\&T BoK) published by the University Consortium for Geographic Information Science (UCGIS) (DiBiase et al., 2006). The current version of the GI $\mathrm{S} \& \mathrm{~T}$ BoK is the most comprehensive guideline for GISc curricula development and is used in many countries throughout the world (DiBiase et al., 2006; Reinhardt, 2011; Du Plessis \& Van Niekerk, 2014).

Table 3. SDI topics

\begin{tabular}{ll}
\hline SDI topic & Description \\
\hline Fundamental GISc & $\begin{array}{l}\text { Fundamental GISc knowledge, such as cartographic principles, geographic } \\
\text { information and spatial reasoning, geographic information system (GIS) } \\
\text { and the global positioning system (GPS). }\end{array}$ \\
\hline $\begin{array}{l}\text { Spatial Data } \\
\text { Infrastructures }\end{array}$ & $\begin{array}{l}\text { The concept of an SDI is, its purpose, benefits, history, trends and case } \\
\text { studies. }\end{array}$ \\
\hline Data Sharing & $\begin{array}{l}\text { Data sharing issues, such as data usability, quality, metadata, and } \\
\text { information systems. }\end{array}$ \\
\hline Standards & Standards, interoperability and harmonisation of data and services. \\
\hline Technology & $\begin{array}{l}\text { Hardware, software, web services, networks and other technological issues } \\
\text { relevant to SDIs. }\end{array}$ \\
\hline Policies \& Legislation & Policies and/or legislation, including license agreements, relevant to SDIs. \\
\hline People & $\begin{array}{l}\text { Topics related to the people aspect of SDIs, such as organisational issues, } \\
\text { capacity building, human resources, marketing, awareness and community } \\
\text { support. }\end{array}$ \\
\hline Economics & $\begin{array}{l}\text { Economic studies about SDIs and spatial information, e.g. on the value of } \\
\text { spatial information, funding models and the return on investment of an } \\
\text { SDI. }\end{array}$ \\
\hline
\end{tabular}

Source: The table has been derived using secondary data during the research based on a literature review, books and consultation workshops.

Some of the SDI topics in Table 3 overlap with each other. For example, Standards and Data Sharing both include metadata standards. Nevertheless, arranging the different knowledge areas and skills into a number of SDI topics helps to 
understand and compare them with curricula. Dependencies between different SDI topics also exist. For example, Data Sharing, as well as some of the other SDI topics, is dependent on Fundamental GISc.

The SDI topics are further described through sample objectives at different incremental learning levels using Bloom's taxonomy in Table 4. The six levels of Bloom's taxonomy (Bloom, 1956) are: knowledge, comprehension, application, analysis, synthesis and evaluation. The fundamental idea behind Bloom's taxonomy is that one needs to build a solid foundation at the lower levels to be able to reach higher levels of learning. While revisions of Bloom's taxonomy have been published (Marzano \& Kendall, 2007), the original taxonomy is still widely used in curriculum development (DeMers, 2009; Pappas et al., 2012; Kidwell et al., 2013).

Seven of the eight SDI topics are described in Table 4 together with learning objectives and the six levels of Bloom's taxonomy to explain what is meant by the SDI topic name. The SDI topic, Fundamental GISc, is sufficiently covered in the academic model of the South African geomatics professional body (see also subsequent section), as well as in GISc curricula accredited according to the model, and is therefore not included in Table 4.

Table 4. Seven SDI topics and objectives at different levels of competence using Bloom's taxonomy

\begin{tabular}{|c|c|c|}
\hline SDI topic & Level & Objective \\
\hline Spatial Data & Evaluation & Evaluate an SDI, e.g. the success or failure of an SDI. \\
\hline \multirow[t]{5}{*}{ Infrastructure } & Synthesis & Design activities and operational plans for an SDI. \\
\hline & Analysis & $\begin{array}{l}\text { Analyse the elements of an SDI, their relationships and } \\
\text { interaction. }\end{array}$ \\
\hline & Application & $\begin{array}{l}\text { Discuss the impact of changes to a particular part or aspect } \\
\text { of an SDI. }\end{array}$ \\
\hline & Comprehension & $\begin{array}{l}\text { Explain in your own words what an SDI is, how SDIs } \\
\text { develop and evolve, and identify an SDI (e.g. distinguish } \\
\text { between an SDI and a corporate GIS). }\end{array}$ \\
\hline & Knowledge & $\begin{array}{l}\text { Remember what an SDI is, how it differs from a GIS, the } \\
\text { SDI principles, benefits of an SDI, names of SDIs, history, } \\
\text { trends. }\end{array}$ \\
\hline \multirow[t]{6}{*}{ Data Sharing } & Evaluation & Evaluate different data sharing mechanisms. \\
\hline & Synthesis & $\begin{array}{l}\text { Design a spatial data sharing mechanism, e.g. a metadata } \\
\text { specification. }\end{array}$ \\
\hline & Analysis & $\begin{array}{l}\text { Analyse the elements of a data sharing mechanism, such as } \\
\text { metadata, their relationships and interactions. }\end{array}$ \\
\hline & Application & $\begin{array}{l}\text { Adjust a given metadata specification to include additional } \\
\text { information for data sharing purposes. }\end{array}$ \\
\hline & Comprehension & $\begin{array}{l}\text { Describe how to prepare spatial data and corresponding } \\
\text { metadata. }\end{array}$ \\
\hline & Knowledge & $\begin{array}{l}\text { Remember what data sharing, usability, quality and } \\
\text { metadata are. }\end{array}$ \\
\hline \multirow[t]{3}{*}{ Standards } & Evaluation & Evaluate different standards and their implementations. \\
\hline & Synthesis & Develop a standard or a profile of an existing standard. \\
\hline & Analysis & Analyse different standards, their relationships and \\
\hline
\end{tabular}




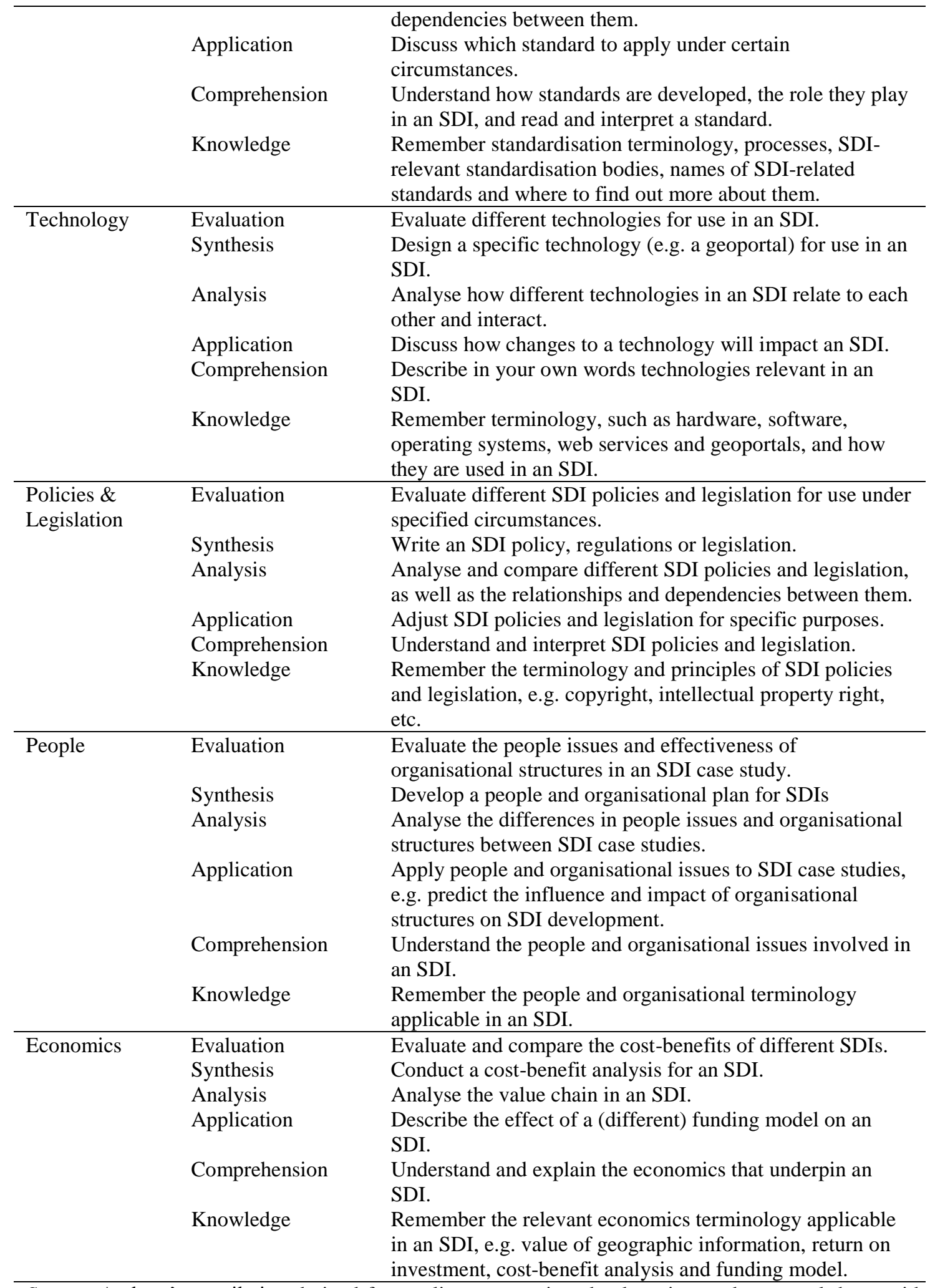

Source: Authors' compilation derived from a literature review, book review and two workshops with members of the South African GISc industry. 


\section{Results of the qualitative comparison of the academic model against the SDI knowledge and skills requirements}

Five of the thirteen themes in the academic model of the South African geomatics professional body overlap only with Fundamental GISc in the list of SDI topics. These themes are Mathematics, Applied Mathematics and Statistics; Physics; Photogrammetry and Remote Sensing; Coordinate Systems and Map Projections; and Geographical Science. For two of the themes (Category-specific Research Project and Electives) the academic model does not specify any details. Universities and/or students have the option to include SDI topics in these two themes. The remaining six themes include topics that also appear in the list of SDI topics identified in this research (Tables 3 and 4), as described in the subsequent paragraphs.

'Spatial data infrastructure' is listed among many other topics under the Geospatial Information Science theme in the academic model. Many of the other topics under this theme refer to the more fundamental aspects of GISc, such as the 'nature of geographic information', 'data acquisition', 'data structures', 'spatial analysis', etc., leaving little time for specialisation in SDI topics. The academic model specifies a total of 175 lecture hours for this theme. This allows time for SDI-related topics at the knowledge and comprehension levels, but there is limited time for higher levels of learning, other than through research work and/or the selection of related SDI topics as electives.

The SDI topic, Data Sharing, can be found in the academic model under a number of themes: Information Technology (e.g. 'security of systems and information', 'data warehouses'), Geospatial Information Science (e.g. 'metadata and geo-libraries') and Data Acquisition (e.g. 'data integration', 'data transfer formats', 'metadata collection'). The fact that this SDI topic is included in more than one theme under multiple topics suggests that the model provides more time and that higher levels of learning are possible compared to other SDI topics.

The Standards SDI topic can be found in the Geospatial Information Science and Data Acquisition themes of the academic model. 'Standards for geospatial information' and 'data standards' are listed respectively as topics for the two themes. The academic model for professional registration specifies 175 and 65 contact hours respectively for these themes. Both themes have a long list of topics, many of these quite fundamental to GISc, and the model thus provides limited contact time to spend on the Standards SDI topic at higher learning levels. 
The Technology SDI topic is mainly found in the Information Technology theme of the academic model. Amongst others, 'introduction to computers and networks', 'computer literacy', 'programming', 'system development' and 'database technology' are listed for this theme. The academic model prescribes a total of 75 contact hours, which should be enough to cover knowledge and comprehension, possibly application, and limited learning at the level of analysis, synthesis and evaluation. From an SDI point of view, important omissions from the list of topics in the academic model are (geospatial) web services and geoportals.

The SDI topic, Policies \& Legislation, is referred to in more than one theme of the academic model. 'Labour legislation', 'taxation' and 'contract law' are listed under the Business and Project Management theme in the academic model, for which a total of 25 contact hours are specified. 'Partnership law' and 'SA Council for Professional and Technical Surveyors (including legislation and rules)' are listed under the Professional Practice and Ethics theme of the academic model, also with a minimum of 25 contact hours. 'Intellectual property and copyright' and 'privacy rights' are listed under the 3D-Modeling/Cartography/Visualisation theme.

Apart from the requirements in the academic model, a candidate for professional registration has to pass a law exam of the geomatics professional body, which covers relevant GISc legislation, such as the Spatial Data Infrastructure Act 54 of 2003 (South Africa, 2003), the Promotion of Access to Information Act 2 of 2000 (South Africa, 2000), the Electronic Communications and Transactions Act 25 of 2002 (South Africa, 2002) and the South African Geographical Names Council Act 118 of 1998 (South Africa, 1998). From the above one can thus infer an emphasis on legislation in the professional registration of GISc professionals, however, it is not clear from the model at which learning levels students have to deal with legislation.

The SDI topic, People, can be found in the academic model under the Business and Project Management theme (e.g. 'human resource management'), as well as under the Professional Practice and Ethics theme (e.g. 'professional ethics', 'client relationships' and 'social responsibility'). For each theme, the model prescribes a minimum of 25 contact hours, leaving limited time for higher learning levels. Organisational issues, such as organisational structures and planning, are not included in the academic model.

The Economics SDI topic of the framework can be found in the academic model as 'financial management', 'management accounting', 'taxation' and 'costing' under 
the Business and Project Management theme, and as 'information economics' under the 3D-Modeling/Cartography/Visualisation theme. Other economic concepts relevant to an SDI, such as the value of geographic information, the value chain of geographic information, cost-benefit analysis and return on investment are not specified in the academic model.

\section{Discussion of the results}

The qualitative comparison of the academic model against the SDI knowledge and skills requirements reveals that all SDI topics are included in some way or other, albeit minimally in some cases, in the academic model. Data Sharing and Polices \& Legislation are specified in more detail and with more prescribed contact hours in the academic model, than other SDI topics. Once SASDI has developed further, the inclusion of SASDI-specific SDI topics (e.g. SDI portal, SDI standards, etc.) in the academic model should be considered.

GISc professionals with a tertiary education based on the academic model contribute and participate in SASDI in different capacities. Therefore, it is not necessary to include all SDI topics to the highest learning level of Bloom's taxonomy in the academic model. However, one can expect that experts in specific SDI topics will be required to realise SASDI. For them, alternative training and education opportunities are required. Some already exist as a result of demand in other fields, for example, special courses in organisational issues and economics. Others will have to be custom-made for SASDI, e.g. on SDIs, SASDI and geographic information standards.

A variety of competencies in knowledge, skills, behaviours and attitudes are required in the acquisition, processing, storing, dissemination and effective utilisation of data, in order to ensure the success of an SDI (Masser, 2005). The variety of SDI topics in the conceptual framework confirms the cross-disciplinary nature of SDIs. A GISc professional does not have to be an expert in each topic, but requires basic knowledge and skills in many different fields and sometimes has to combine knowledge from different fields before being able to apply it. For example, a GISc professional does not have to be a legal expert, but should have enough legal background to understand the application of legal principles to the sharing of geographic information in an SDI. 
The comparison of the themes in the academic model against the list of SDI topics was problematic because the model does not specify learning levels. Future versions of the model should be refined to specify minimum learning levels for topics in different themes, for example, based on the learning levels specified in Bloom's taxonomy. Such a refinement will clarify the baseline for the education of GISc professionals and facilitate the accreditation of academic programmes and the evaluation of registration applications.

Further research needs to investigate approaches for the inclusion of SDI topics in a curriculum: one can either include SDI in all modules, or develop an SDI-specific module. The limited number of textbooks on SDIs (Rautenbach \& Coetzee, 2013) suggests that SDI topics are typically embedded in other modules. Additional research is required to confirm this and to compare the effectiveness of the two approaches.

This evaluation considered the education and training of GISc professionals in South Africa. However, many other types of professionals, engineers and scientists participate in an SDI. For example, computer scientists working on the implementation of a geoportal should understand at least the basics of SDIs and geospatial data sharing. Currently, there are limited opportunities for them to improve their SDI knowledge and skills.

\section{Conclusion}

In this article the academic model of the South African geomatics professional body was qualitatively compared against industry's understanding of the SDI knowledge and skills requirements for GISc professionals. The requirements were compiled and organized into a number of SDI topics based on a review of scientific literature, a book review and input from the South African GISc industry. Eight SDI topics were identified: Fundamental GISc, Spatial Data Infrastructures, Data Sharing, Standards, Technology, Policies \& Legislation, People and Economics. The academic model specifies the academic requirements for GISc professional registration in South Africa and is also used for the accreditation of university programmes. The comparison revealed that all SDI topics are included in some way or the other in the academic model. Data sharing and Policies \& Legislation are included in more detail and with more contact time than the other topics. However, specific aspects of a number of the SDI topics are not yet covered in the academic model; for example, geoportals, 
organisational structures and planning, the value of geographic information and the value chain of geographic information.

The academic model specifies themes and topics, but not learning levels, which makes it difficult to assess a specific curriculum against the academic model. The baseline for the education of GISc professionals in South Africa can be clarified by refining the academic model to specify minimum learning levels for topics in different themes. Such a refinement will also facilitate the accreditation of academic programmes and the evaluation of registration applications.

The findings of this study confirm the challenges of evaluating and comparing descriptions of education and training requirements, exemplified in this research by the themes in the academic model. While a theme description may suggest that relevant topics are sufficiently covered, closer inspection could reveal significant omissions in the content. Comparing content alone is also not adequate, as the content can be taught at different learning levels. This underlines the importance of a sufficiently detailed description of a baseline for the assessment of curricula and qualifications by a professional body. But even if a detailed description of a baseline exists, detailed module descriptions and learning levels are rarely included on academic transcripts submitted with applications for GISc professional registration.

Education and continued education are essential to realising an SDI in South Africa, which is essential for the sustainable development of the country. The research presented in this article contributes to the understanding of the skills and knowledge required by practitioners involved in any SDI, not only SASDI. The findings can be used to guide educators, learners and SDI implementers all over the world to prepare, select and/or evaluate education programmes and appropriate modules. Proper GISc education and awareness of the benefits of SDIs will counter the current decline in the management, distribution and accessibility of geospatial data, contributing to cost saving and positive developmental implications for countries. The research contributes to a better understanding of the often-neglected human resource component of an SDI (Hendriks et al., 2012).

It is recommended that future research should include a comparison of the UCGIS GI S\&T BoK (DiBiase et al., 2006) against the SDI topics presented in this article. The GI S\&T BoK is widely used internationally for GISc curricula development. It is currently being reviewed and the results from such a comparison may inform the reviewers on possible gaps in the GI S\&T BoK. 
What is the message for other educators? It is necessary to review a GISc curriculum to verify that SDI topics are adequately covered. The list of SDI topics presented in this article could be used to start with, adding topics specific to the SDIs of countries and regions students are likely to encounter in their work. Educators and SDI stakeholders should engage with each other to understand what these SDIspecific topics should be.

\section{Acknowledgements}

We thank members of South Africa's CSI sub-committee on Education and Training and individuals from the GIS industry, for their contributions during the two workshops on SASDI education and training held in November 2011 and July 2012.

This research was partly supported by a GSDI Small Grant Award, titled 'Developing a framework for South African SDI education and training'.

The authors are grateful for the comments from the editor and anonymous reviewers, which helped us to improve the article substantially.

\section{References}

Beconytê, G., Govorov, M., Ningal, T.G., Paršeliūnas, E., \& Urbanas, S. (2008). Geographic information e-training initiatives for national spatial data infrastructures. Baltic Journal on Sustainability, 14(1), 11-28.

Bloom, B.S. (1956). Taxonomy of Educational Objectives. Allyn and Bacon publisher: Boston, USA.

Boes, U., \& Pavlova, R. (2011). The education challenge for the geodetic and spatial data infrastructure profession. Serbian Geodetic Congress. Belgrade, 2-7.

Coetzee, S., Eksteen, S., \& Grundling, C. (2013). Sustainable Development ：The Contribution from GISc Education in South Africa. South African Journal of Geomatics, 2(3), 246-259.

Crompvoets, J., \& Bregt A. (2005). Assessing the worldwide developments of national spatial data clearinghouses. International Journal of Geographical Information Science (IJGIS), 18(7), 665-689.

DeMers, M.N. (2009). Using Intended Learning Objectives to Assess Curriculum Materials: the UCGIS Body of Knowledge. Journal of Geography in Higher Education, 33(1), $70-77$.

DiBiase, D., DeMers, M., Johnson, A., Kemp, K., Luck, A.T., Plewe, B., \& Wentz, E. (Eds.). (2006). Geographic Information Science and Technology Body of Knowledge. Association of American Geographers: Washington, USA. 
Du Plessis, H., \& van Niekerk, A. (2013). A Comparison of Geographical Information Science Competency Requirements. South African Journal of Geomatics, 2(3), 206217.

Du Plessis, H., \& van Niekerk, A. (2014). A New GISc Framework and Competency Set for Curricula Development at South African Universities. South African Journal of Geomatics, 3(1), 1-12.

Eelderink, L., Crompvoets, J., \& De Man, W. (2008). Towards key variables to assess national spatial data infrastructures (NSDIS) in developing countries. In J. Crompvoets, A. Rajabifard, B. van Loenen, \& T. Delgado (Eds.). A Multi-View Framework to Assess SDIs. GSDI Association, 207-325.

Electronic Communications and Transactions Act, 25, South Africa (2002).

Flamholtz, E., \& Lacey, J. (1981). Personnel Management: Human Capital Theory and Human Resource Accounting. Institute of Industrial Relations: Los Angeles, USA.

Geomatics Professions Act, 19, South Africa (2013).

Georgiadou, Y., Puri, S.K., \& Sahay, S. (2005). Towards a potential research agenda to guide the implementation of Spatial Data Infrastructures-A case study from India. International Journal of Geographical Information Science, 19(10), 1113-1130.

Grus, L., Crompvoets, J., \& Bregt, A.K. (2010). Spatial data infrastructures as complex adaptive systems. International Journal of Geographical Information Science, 24(3), 439-463.

Hendriks, P.H.J., Dessers, E., \& van Hootegem, G. (2012). Reconsidering the definition of a spatial data infrastructure. International Journal of Geographical Information Science, 26(8), 1479-1494.

Hjelmager, J., Moellering, H., Cooper, A., Delgado, T., Rajabifard, A., Rapant, P., Danko, D., Huet, M., Laurent, D., Aalders, H., Iwaniak, A., Abad, P., Düren U., \& Martynenk, A. (2008). An initial formal model for spatial data infrastructures. International Journal of Geographical Information Science, 22(11-12), 1295-1309.

Jackson, M.J., \& Gardner, Z. (Eds.) (2011). Using Spatial Data Infrastructures for Monitoring Development Outcomes: A Manual for Developing Countries. Retrieved from http://lgosmgb2.nottingham.ac.uk/elogeowiki/index.php/World Bank SDI Report.

Kidwell, L.A., Fisher, D.G., Braun, R.L., \& Swanson D.L. (2013). Developing Learning Objectives for Accounting Ethics Using Bloom's Taxonomy. Accounting Education: An International Journal, 22(1), 44-65.

Le Deist, F.D., \& Winterton, J. (2005). What is Competence?. Human Resource Development International, 8(1), 27-46. 
Marzano, R.J. \& Kendall, J.S. (2007). The New Taxonomy of Educational Objectives, London: Sage Publications.

Masser, I. (2005). GIS worlds: Creating spatial data infrastructures. ESRI Press: Redlands, USA.

Masser, I. \& Campbell, H. (1991). Conditions for the effective utilisation of computers in urban planning in developing countries. Computers, Environment and Urban Systems, 1991(1-2): 55-67.

Messina, J.P., \& Shortridge, A. (2006). Moving beyond the Specialization: the Development of a Bachelor of Science Program in Geographic Information Science at Michigan State University. Geocarto International, 21(2), 67-73.

Nebert, D. (Ed). (2009). The SDI Cookbook. Global Spatial Data Infrastructure (GSDI) Association.

Pappas, E., Pierrakos, O., \& Nagel, R. (2012). Using Bloom's Taxonomy to teach sustainability in multiple contexts. Journal of Cleaner Production, 1-11.

Professional and Technical Surveyors' Act, 40, South Africa (1984).

Promotion of Access to Information Act, 2, South Africa (2000).

Rautenbach, V., Coetzee, S., Smit, J., Muzondo, I., \& du Plessis, H. (2012). Identifying the target audiences, media and messages for SDI education and training in South Africa. GISSA Ukubuzana 2012. Kempton Park, South Africa, 1-9.

Rautenbach, V., \& Coetzee, S. (2013). Books for SDI Education and Training in South Africa. 26th International Cartographic Conference. Dresden, Germany, 1-15.

Reinhardt, W., 2011. Geoinformatics education in different disciplines - Challenges approaches and experiences. In Hubeau M., Steenberghen T., van Balen, K., van Orshoven, J. and Vileikis O. (Eds.). GIS-education in a changing academic environment. Workshop proceedings: LeGIO workshop, KU Leuven, ISBN 978-908826-217-3, 21-28.

Richter, C., Miscione, G., \& Georgiadou, Y. (2010). Conceptualizing people in SDI literature : Implications for SDI research and development. International Journal of Spatial Data Infrastructures Research, 5, 286-325.

Schulze, U., Kanwischer, D., \& Reudenbach, C. (2013). Essential competences for GIS learning in higher education: a synthesis of international curricular documents in the GIS\&T domain. Journal of Geography in Higher Education, 37(2), 257-275.

Skender, I. (2013). Challenge of capacity building and education in the sector of SDI. Conference on Capacity Building and Education in Geomatics, SDI and Land Administration, Durrës, Albania.

South African Geographical Names Council Act, 118, South Africa (1998).

Spatial Data Infrastructure Act, 54, South Africa (2003). 